\title{
Natural product inhibitors of acetyl-lysine erasers in the prevention and treatment of heart failure
}

\author{
*Levi W. Evans ${ }^{1,2}$, *Samantha S. Romanick ${ }^{1,3}$, Bradley S. Ferguson ${ }^{1}$
}

${ }^{1}$ Department Agriculture, Nutrition, \& Veterinary Sciences, University of Nevada, Reno, USA; ${ }^{2}$ Environmental Sciences and Health, University of Nevada, Reno, USA; ${ }^{3}$ Cellular \& Molecular Pharmacology and Physiology, University of Nevada, Reno, USA

*Equal Contribution

Corresponding author: Bradley S. Ferguson, $\mathrm{PhD}$, Department of Agriculture, Nutrition and Veterinary Science, University of Nevada Reno, 1664 N. Virginia St., Reno, NV, USA

Submission Date: June $30^{\text {th }}$, 2017, Acceptance Date: August 22 ${ }^{\text {nd }}$, 2017, Publication Date: August $31^{\text {st }}, 2017$

Citation: Evans LW, Romanick SS, Ferguson BS. Natural product inhibitors of acetyl-lysine erasers in the prevention and treatment of heart failure, Functional Foods in Health and Disease 2017; 7(8): 577-603. https://doi.org/10.31989/ffhd.v7i8.376

\begin{abstract}
Heart failure (HF) is a major public health concern, with five-year mortality rates following first admission for HF being approximately $50 \%$, thereby stressing the need for novel therapeutic approaches. Histone deacetylases (HDACs) govern lysine acetylation of histone tails that regulates nucleosmal DNA. HDAC inhibitors have emerged as efficacious therapies in pre-clinical models of HF. Interest in diet-gene interactions has given rise to the study of 'food bioactives' as epigenetic regulators of gene expression that control human health and disease. These reports demonstrate that bioactive food compounds regulate epigenetic marks that link diet to gene regulation. In fact, others have also shown that bioactive compounds can target HDACs for inhibition; accordingly, bioactive food compounds offer unique opportunities for therapeutic intervention and prevention of heart failure. Lastly, there is emerging interest into how these food bioactives function together or as additives within foods 'functional foods' to regulate epigenetic disease. This review will highlight bioactive compound HDAC inhibitors and their role in the heart.
\end{abstract}

Keywords: acetylation, bioactive compounds, dietary HDAC inhibitors, HDACs, histone deacetylases

\section{INTRODUCTION}

Approximately 5.7 million U.S. adults (>20 yrs) experience heart failure (HF), with projections estimating greater than 8 million adults diagnosed with HF by 2030 [1], partially due to the growing number of elderly adults in the U.S. Moreover, the increase in HF prevalence is projected to contribute to direct annual medical costs growth from $\$ 21$ billion to $\$ 53$ billion, with indirect medical costs projected to increase from $\$ 31$ billion to $\$ 70$ billion [2]. From 1979 to 2000, HF survival rates improved, due to improvements in the standards of care, including current therapeutic treatments such as $\beta$-blockers and angiotensin converting enzyme inhibitors (ACEi). 
However, five-year mortality rates still remain high, being approximately $50 \%$ [1]. These statistics stress the need for improved therapeutic approaches capable of managing and or preventing this disease [3].

The heart undergoes remodeling in response to stress such as hypertension. Cardiac remodeling is characterized by muscle cell hypertrophy, apoptosis, and fibrosis, generally resulting in cardiac dysfunction and HF [4]. $\beta$-blockers and ACEi, in addition to other standard HF therapeutics, regulate signaling cascades stimulated by cell surface receptors to prevent cardiac remodeling and pump dysfunction [5]. However, there is redundancy across signaling pathways, in which inhibition of a particular cascade may not be sufficient to completely block or reverse pathological cardiac remodeling and failure. Therefore, it has been postulated that drugs designed to target shared downstream mediators of these signaling pathways would be more efficacious for the treatment of HF. This has given rise to the suggestion that drugs designed to target the epigenome have the potential to inhibit shared downstream mediators of pathological signaling.

One such group of epigenetic mediators, histone deacetylases (HDACs), have shown significant promise in animal studies of HF [3, 6-11]. HDACs have historically been characterized as regulators of nucleosomal DNA, in which they remove acetyl groups from lysine residues on histone tails. Removal of acetyl groups has classically been linked to heterochromatin formation and subsequently transcriptional repression. Conversely, acetylation of histone proteins on lysine residues by histone acetyltransferases (HATs) promotes transcriptional activation [3, 12-14] (Figure 1).
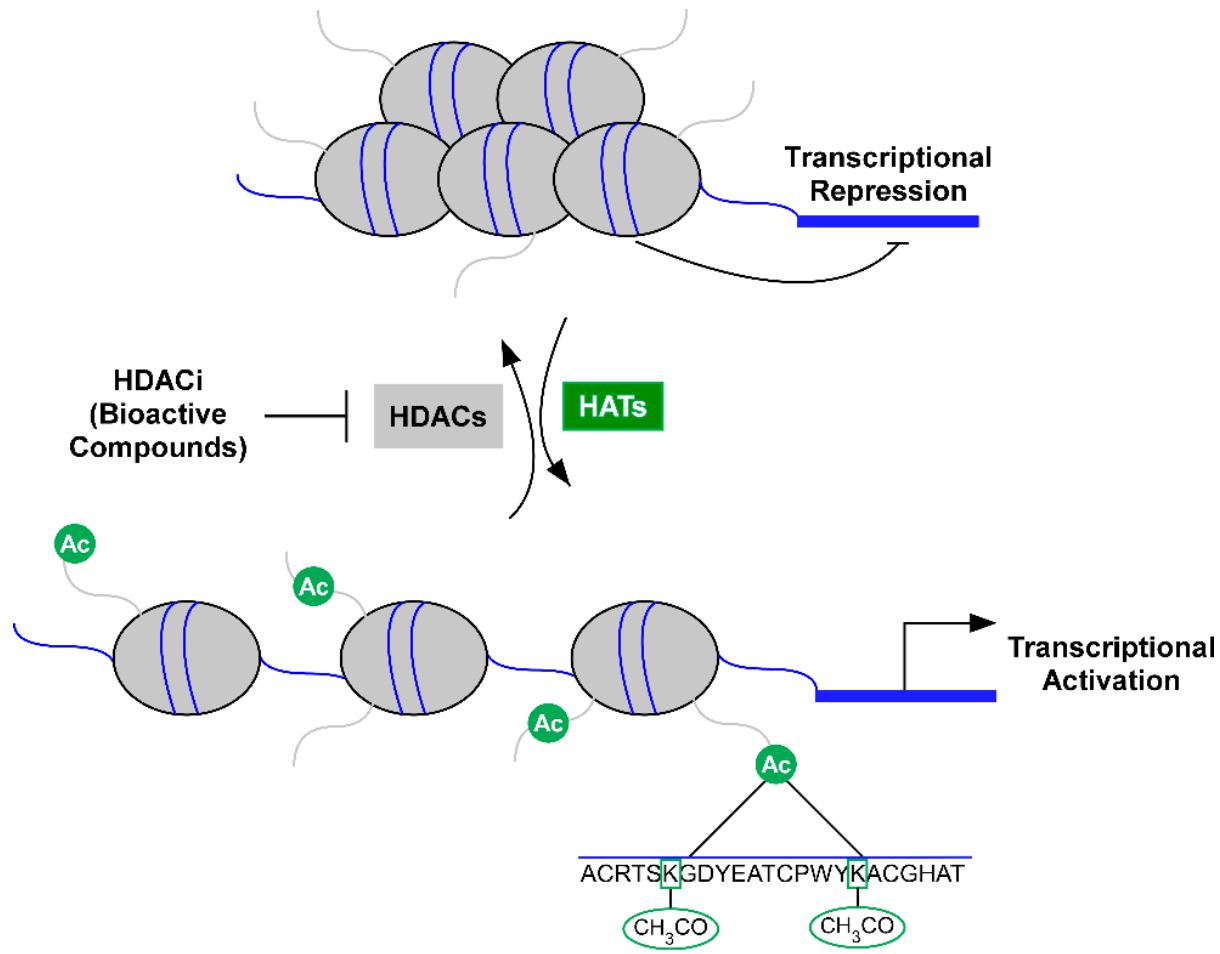

Figure 1. Mechanisms of chromatin remodeling by lysine acetylation. Histone acetyl transferases (HATs) acetylate lysine residues on histone tails resulting in transcriptional activation. Conversely, histone deacetylases (HDACs) deacetylate lysine residues resulting in transcriptional repression. HDAC inhibitors (HDACi) inhibit HDACs from removing acetyl marks from lysine residues and thus alter gene expression. 
There are currently eighteen mammalian HDACs that have been grouped into four distinct classes. Class I HDACs (HDACs 1, 2, 3, and 8), class II HDACs (HDACs 4, 5, 6, 7, 9, and 10) and the lone class IV HDAC (HDAC 11) are zinc dependent HDACs, with zinc being required for deacetylase activity. Moreover, class II HDACs are subdivided into IIa and IIb. Class III HDACs (SIRTs 1-7) is comprised of the sirtuin family. Sirtuins are nicotinamide adenine dinucleotide (NAD+) dependent; NAD+ is a required cofactor for deacetylase activity [13, 14] (Figure 2). Inhibition of zinc dependent HDACs is efficacious in animal models of heart failure [3, 6-11]. Therefore, this review will not discuss sirtuins.

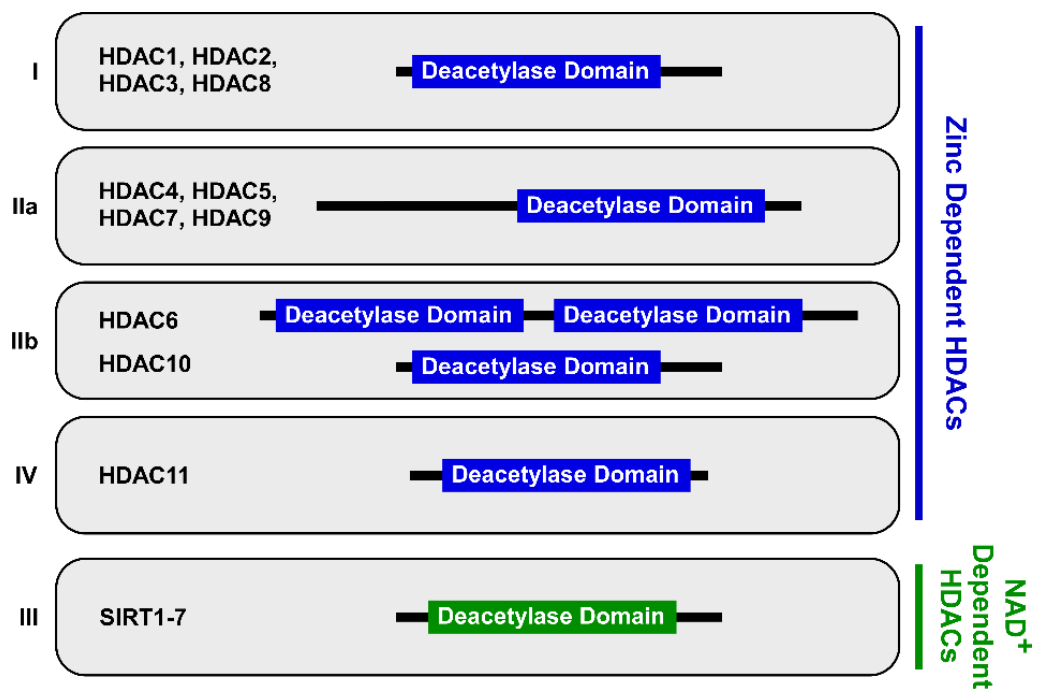

Figure 2. Histone deacetylases (HDACs) are categorized into distinct classes. There are eighteen mammalian HDACs that have been divided into four different classes. Class I, IIa, IIb, and IV HDACs require zinc for catalytic activity, while class III HDACs (i.e. sirtuins) require nicotinamide adenine dinucleotide+ (NAD+) for deacetylase activity.

\section{HDAC Inhibitors}

Currently, there are 3 FDA approved HDAC inhibitors (Vorinostat, Romidepsin, and Panobinostat) for the treatment of T-cell lymphoma, with at least 12 different HDAC inhibitors in some phase of clinical trials for the treatment of various cancers $[15,16]$. In addition to these FDA approved compounds, valproic acid is a short chain fatty acid HDAC inhibitor available for human use. Although valproic acid was initially used to treat epilepsy, valproic acid has become prominent for the treatment of other neurological-related ailments [17]. This interest in HDAC inhibitors for the treatment of various diseases has driven medicinal chemistry efforts to develop broad spectrum, class-selective and isoform-specific HDAC inhibitors.

The classical HDAC inhibitor pharmacophore consists of a three-part structure: 1) a zincbinding motif capable of binding to the active site, 2) a surface recognition domain that interacts with residues near the active site, and 3) a hydrocarbon linker that connects the motifs to the domain. HDAC inhibitors were historically classified into four groups: hydroxamic acids, shortchain fatty acids, benzamides, and cyclic peptides [13, 14, 18]. However, ortho-aminoanilide HDAC inhibitors have recently been identified [19], which suggests there is other unknown HDAC 
inhibitor groups. Potencies and HDAC class selectivity differ within these classes [14]. Hydroxamic acid HDAC inhibitors, such as Trichostatin A and SAHA (i.e. Vorinostat), are panHDAC inhibitors that possess strong zinc-chelating properties. These are potent, low nanomolar HDAC inhibitors. Conversely, short-chain fatty acids, such as valproic acid and sodium butyrate, tend to be weak, millimolar HDAC inhibitors. Their fatty acid physiochemical properties afford advantages in uptake and transportation. However, their nonspecific biochemical functions limit target specificity and are thereby potentially disadvantageous. Benzamide HDAC inhibitors such as MS-275 have a classical benzene ring as the hydrocarbon linker and an amide motif. Benzamide HDAC inhibitors are selective for class I HDACs (HDACs 1, 2, and 3) [18]. Ortho-aminoanilide have a similar structure to the benzamide HDAC inhibitors. Cyclic peptide HDAC inhibitors, such as apicidin and Romidepsin, are often highly potent and incorporate alkyl-linking motifs as well as various zinc-binding groups. Cyclic peptide HDAC inhibitors tend to be selective for class I HDACs [20].

\section{HDAC inhibitors and Heart Failure}

Pan and isoform-selective HDAC inhibitors have been shown to block and potentially reverse cardiac remodeling in the heart; these studies have been extensively reviewed [3, 6, 7, 11, 21, 22]. For instance, treatment with the broad spectrum HDAC inhibitor Trichostatin A (TSA), has been shown to block and even reverse cardiac remodeling and dysfunction in rodent models of heart failure [23-25]. Similarly, MPT0E014 (pan-HDAC inhibitor) reduced left ventricular wall thickening and improved the systolic function in rats exposed to isoproterenol-mediated HF. These improvements were linked to pathogenetic changes in gene expression and intracellular signaling [26]. Recently, SAHA, an FDA approved HDAC inhibitor, was shown to decrease infarct size and improved systolic heart function in a rabbit model of ischemia/reperfusion (I/R) injury. These findings are significant as the delivery of SAHA before or during reperfusion was effective [8], suggesting there is therapeutic potential for human HF.

More specifically, we have reported that class I HDACs regulate cardiac hypertrophy and fibrosis [27, 28], in which class I-selective HDAC inhibition blocked cardiac myocyte hypertrophy and angiotensin II-dependent fibrosis. These findings have been verified in additional models of $\mathrm{HF}$; treatment with mocetinostat was shown to alleviate and improve HF-mediated actions in vivo and in vitro [29, 30], while treatment with class I-selective short chain fatty acid HDAC inhibitors ameliorated cardiac hypertrophy and fibrosis in a rat infarct model [31]. In addition to class Iselective HDAC inhibitors, inhibition of class IIb HDACs, in particular HDAC6, have been shown to improve cardiac function in rodent models of HF. Inhibition of HDAC6 imparts cardiac protection via improvements in myofibril contractility [32] as well as decreased cardiac proteotoxicity via regulation of autophagy-mediated protein aggregate degradation [33].

These studies highlight the potential for HDAC inhibitors in the treatment of heart failure. However, many of these synthetic HDAC inhibitors have adverse effects and toxicities, in addition to also potentially being cost prohibitive [34]. As a result, there has been a shift in today's population toward natural compounds for use in medicine, which has increased demand for natural compound therapeutic discovery $[35,36]$. Additionally, there has been a push to understand how bioactive food compounds regulate epigenetic marks in the control of gene expression that impacts human health and disease. The remainder of this review will focus on bioactive compound HDAC inhibitors and their potential as therapeutics for HF. 


\section{Bioactive HDACi}

The benefits of consuming fruits, vegetables, and whole grains have been well-studied and wellestablished [37]. Research has now shifted to understand the molecular actions for how 'food bioactives' or bioactive compounds found in foods help keep us healthy. Bioactive compounds are found in plants, herbs, and other foods stuffs and have typically been linked to plant pigmentation, growth, and pest resistance; however, new findings demonstrate the importance for these bioactives in human health and disease [35, 38, 39]. Moreover, accumulating evidence has shown that dietary bioactive food compounds alter epigenetic marks that link diet-gene interactions in a manner that impacts pathogenetic mechanisms involved in the heart [40, 41].

Short-chain fatty acid HDAC inhibitors have been widely studied in the heart. Short-chain fatty acids are typically produced by gastrointestinal bacteria via fermentation of fibrous foods such as fruits, vegetables, and whole grains. Treatment with short-chain fatty acid HDAC inhibitors tributyrin or valproic acid have been shown to block cardiac hypertrophy and fibrosis in a rat infarct model [31]. Additionally, sodium butyrate was shown to attenuate cardiac hypertrophy and fibrosis and increase systolic function in pre-clinical rodent models of heart failure via inhibition of class I HDAC activity [31, 42]. As short-chain fatty acid HDAC inhibitors have been used successfully in humans for neurological-related ailments, these data suggest potential for these compounds in human HF. However, it should be noted that short-chain fatty acids regulate various biochemical pathways, independent of HDAC activity, and could thereby improve heart health through multiple mechanisms of action [17].

Other bioactive food compound HDAC inhibitors have also recently been identified [39, 43, 44]. For instance, curcumin has been shown to regulate HDACs in various cancer models [45, 46]. Similar to short-chain fatty acids, curcumin has also been shown to possess multiple biological functions including the inhibition of histone acetyl transferases (HATs) [45]. In this report, curcumin-mediated inhibition of p300 HAT activity led to GATA4 transcriptional repression; cardiac function was subsequently improved in a rodent model of hypertension [45]. Sulforaphane is another dietary HDAC inhibitor with recent interest in the cancer field. Sulforaphane is commonly found in broccoli and has been shown to inhibit HDAC activity and increase histone acetylation [39, 44, 47, 48]. While most of these studies have focused on anti-carcinogenic actions for sulforaphane, other reports have shown the benefit of sulforaphane treatment in models of diabetic cardiomyopathy. Finally, our group demonstrated that grape seed procyanidin extract could significantly inhibit HDAC activity in rat liver, concomitant with reductions in serum triglycerides [49].

The field of nutrigenomics and nutri-epigenetics has rapidly advanced in the last decade leading to increased reports demonstrating the potential impact for food compounds in the regulation of diet-epigenetic-gene interactions in human health and disease [38, 39]. However, most of these studies have focused on bioactives for the treatment or prevention of cancer [38, 39, 50], with fewer studies examining the dietary HDAC inhibitors in the heart. Accordingly, we recently screened several isolated bioactive compounds (131 compounds) found in plants, herbs, and food stuffs as potential inhibitors of HDAC activity in the heart [51]. HDACs were specific to the non-sirtuin, zinc-dependent HDACs. We reported that eighteen of these bioactives inhibited HDAC activity. While we are currently investigating the epigenetic actions of these compounds in the heart, a brief review of the literature on these compounds has been summarized below for regulation of HDAC activity and/or cardiac remodeling. A summary of these compounds as regulators of HDAC activity can also be found in Table 1. 
Table 1. Dietary HDAC inhibitors. The table represents the eighteen compounds identified from our initial screen that inhibited class I, IIa, and IIb HDAC activity in [51]. We have included a synopsis of their known HDAC targets below.

\begin{tabular}{|c|c|c|c|}
\hline $\begin{array}{l}\text { Bioactive } \\
\text { Compound }\end{array}$ & Source & Regulation of Acetylation & References \\
\hline Apigenin & $\begin{array}{l}\text { Citrus, chamomile tea, } \\
\text { celery }\end{array}$ & $\begin{array}{l}\downarrow \text { Class I HDACs, Class IIa, \& Class IIb activity; } \\
\uparrow \mathrm{H} 3 \text { \&H4 acetylation on } 21 / \text { waf1 promoter } \\
\downarrow \text { HDAC2, HDAC3, HDAC4, HDAC6, HDAC7 \& } \\
\text { HDAC8 protein expression } \\
\downarrow \text { HDAC } 1 \text { activity \& protein expression }\end{array}$ & [51-54] \\
\hline Baicalein & $\begin{array}{l}\text { Roots of skullcap, } \\
\text { Indian trumpetflower }\end{array}$ & $\begin{array}{l}\downarrow \text { Class I \& IIa HDAC activity } \\
\downarrow \text { HDAC } 4 \& 5 \text { mRNA expression level }\end{array}$ & {$[51,55]$} \\
\hline Baicalin & $\begin{array}{l}\text { Roots of skullcap, } \\
\text { Indian trumpetflower }\end{array}$ & $\begin{array}{l}\downarrow \text { Class I, IIa, \& IIb HDAC activity; } \\
\uparrow \text { SIRT1 (Class III HDAC) protein expression; } \\
\uparrow \mathrm{H} 3 \text { acetylation, } \downarrow \text { HDAC1 protein expression }\end{array}$ & {$[51,56,57]$} \\
\hline Berberine $\mathrm{HCl}$ & Roots, stembark & $\downarrow$ Class I \& IIb HDAC activity & [51] \\
\hline Caffeic acid & $\begin{array}{l}\text { Coffee, artichokes, } \\
\text { wine }\end{array}$ & $\begin{array}{l}\downarrow \text { Class I, IIa, \& IIb HDAC activity; } \\
\downarrow \text { Class III HDAC (SIRT3) down expression } \\
\downarrow \text { HDAC8 activity }\end{array}$ & {$[51,58,59]$} \\
\hline Dihydromyricetin & Moyeam herb & $\downarrow$ Class I, IIa, \& IIb HDAC activity & [51] \\
\hline Emodin & $\begin{array}{l}\text { Rhubarb, buckthorn, } \\
\text { Japanese knotweed }\end{array}$ & $\begin{array}{l}\downarrow \text { Class I, IIa, \& IIb HDAC activity } \\
\downarrow \text { HDAC1 protein expression } \\
\uparrow \text { SIRT1 (Class III HDAC) protein expression }\end{array}$ & {$[51,60,61]$} \\
\hline EGCG & Teas (green, black) & $\begin{array}{l}\downarrow \text { Class I, IIa, \& IIb HDAC activity; } \\
\uparrow \mathrm{H} 3 \text { (K9 \& K9/14) \& H4 (K5, K12 \& K16) } \\
\text { acetylation } \\
\uparrow A c-H 3 \& \downarrow \text { HDAC1 protein expression } \\
\downarrow \text { HDAC1 \& } \uparrow A c-H 4 \text { protein expression } \\
\downarrow \text { HDAC1, 2, 3, \& } 8 \text { HDAC protein expression, } \\
\uparrow p 53 \text { (K373 \& K382) acetylation } \\
\downarrow \text { HDAC1, 2, 3, \& 8 HDAC protein expression } \\
\downarrow \text { HDAC1 \& } 3 \text { mRNA expression level, } \uparrow \mathrm{H} 3 \text { (K9) } \\
\text { acetylation on cTnI promoter }\end{array}$ & {$[51,62-67]$} \\
\hline Gossypol & Parts of cotton plant & $\downarrow$ Class I, IIa, \& IIb HDAC activity & [51] \\
\hline Hematoxylin & Heartwood of tree & $\downarrow$ Class IIb HDAC activity & [51] \\
\hline Indirubin & Glastum, buckwheat & $\downarrow$ Class I \& IIb HDAC activity & {$[51]$} \\
\hline Kaempferol & $\begin{array}{l}\text { Apples, grapes, } \\
\text { broccoli, brussel } \\
\text { sprouts }\end{array}$ & $\begin{array}{l}\downarrow \text { Class I, IIa, \& IIb HDAC activity; } \\
\uparrow \text { Ac-H3 protein expression, } \downarrow \text { Class I, II, and IV } \\
\text { activity }\end{array}$ & {$[51,68]$} \\
\hline Luteolin & $\begin{array}{l}\text { Celery, broccoli, } \\
\text { oranges }\end{array}$ & $\begin{array}{l}\downarrow \text { Class I, IIa, \& IIb HDAC activity; } \\
\uparrow A c-H 3 \text { (K14) \& Ac-H4 (K5) protein expression, } \\
\downarrow \text { HDAC activity on Ac-H3 \& Ac-H4 }\end{array}$ & {$[51,69]$} \\
\hline Morin hydrate & Osage orang, guava & $\downarrow$ Class I \& IIa HDACs & {$[51]$} \\
\hline Myricetin & $\begin{array}{l}\text { Walnuts, berries, red } \\
\text { grapes }\end{array}$ & $\begin{array}{l}\downarrow \text { Class I, IIa, \& IIb HDACs; } \\
\uparrow \text { SIRT1 (Class III HDAC) protein expression }\end{array}$ & {$[51,70]$} \\
\hline Myricitrin & Bayberry root bark & $\downarrow$ Class I, IIa, \& IIb HDACs & [51] \\
\hline Palmatine & Amur cork tree & $\downarrow$ Class I HDACs & [51] \\
\hline Quercetin dihydrate & $\begin{array}{l}\text { Phellodendron } \\
\text { amurense, berries, } \\
\text { grapes }\end{array}$ & $\begin{array}{l}\downarrow \text { Class I, IIa, \& IIb HDACs; } \\
\uparrow \text { SIRT1 (Class III HDAC) protein expression }\end{array}$ & {$[51,70,71]$} \\
\hline
\end{tabular}




\section{Apigenin}

Apigenin is a plant-derived flavanoid found in chamomile, an aromatic oil extracted from flowers or leaves of daisy-like plants which has traditionally been used as an oil or tea for its soothing qualities that aid sleep. With regards to the heart, apigenin has been shown to restore hemodynamic perturbations and left ventricular dysfunction in the diabetic mouse [72]. Additionally, apigenin has been shown to inhibit myocardial ischemia/reperfusion injury [73-75]. Cardio-protective actions of apigenin have been postulated to include regulation of PPAR gamma activity and intracellular signaling cascades such as protein kinase $\mathrm{C}(\mathrm{PKC})$ and p38 mitogen-activated protein kinase [72-74]. However, it should be noted that epigenetic mechanisms have also been attributed to this compound including regulation of micro RNA expression in addition to class I HDAC activity and histone acetylation [51, 52, 76, 77]. Thus, cardio-protective actions for apigenin may also include inhibition of HDAC activity and therefore global regulation of gene expression that is downstream of intracellular signaling events.

\section{Baicalein}

Baicalein is a flavonoid commonly found in the plant Scutellaria baicalensis, which is a member of the mint family. Traditional Chinese and Japanese medicine have used Scutellaria baicalensis as a component of Sho-saiko-to, which is a mixture of seven herbal preparations for the treatment of chronic hepatitis [78]. In the heart, baicalein has been shown to attenuate isoproterenol (ISO)induced myocardial injury via inhibition of NF-kB expression and subsequently inflammation and oxidative stress [79]. Moreover, baicalein has been shown to ameliorate angiotensin II-induced hypertension and cardiac remodeling in addition to LPS-induced cardiac injury. Cardio-protective actions of Baicalein have been attributed to attenuation of intracellular signaling cascades that include AKT, MAPKs, and calcineurin [80-82] as well as suppression of inflammatory gene expression [79]. Our recent findings revealed novel unreported actions for baicalein as a panHDAC inhibitor [51]. Significantly, inhibition of HDACs has been reported to regulate intracellular signaling cascades in cardiac myocytes in addition to changes in gene expression [28], thereby supporting the postulate that baicalein-mediated inhibition of HDACs underlie its cardioprotective actions.

\section{Baicalin}

Baicalin is a flavone that is found in several species of Scutellaria. Baicalin is the glucuronide of baicalein and similarly one of the chemical ingredients found in Sho-saiko-to, an herbal Japanese and Chinese medicine. Like baicalein, baicalin has been reported to inhibit cardiac dysfunction and remodeling in rodent models of chronic pressure-overload, myocardial ischemia and isoproterenol-induced acute myocardial infarction [83-85]. Furthermore, baicalin has been reported to ameliorate pulmonary fibrosis and pulmonary arterial hypertension, which impacts right-sided heart failure [86-88]. Like baicalein, baicalin has been reported to work via attenuation of intracellular signaling cascades and in particular inhibition of MAPKs [85, 87-89]. Unlike baicalein, it has been reported that baicalin can inhibit HDAC2 activity; this was critical for the inhibition of inflammation in a smoke-induced rodent model [90]. Others have reported that baicalin suppresses pain perception in response to spinal cord injury through inhibition of HDAC1 [57]. Likewise, we reported pan-HDAC inhibition with baicalin in bovine cardiac tissue [51]. 
Similar to baicalein, these data imply that cardio-protective actions for baicalin is mediated in part via epigenetic actions for this compound on histone acetylation via attenuation of HDAC activity.

\section{Berberine Hydrochloride (BHCl)}

Berberine is an active ingredient in the Chinese herb Coptis chinensis Franch and has been used for centuries to treat diabetes. Currently, berberine is marketed as an over-the-counter drug sold as berberine hydrochloride $(\mathrm{BHCl})$ to treat gastrointestinal infections in China [91]. Little is known regarding $\mathrm{BHCl}$ in the heart. To our knowledge, only two published articles have focused on the role of $\mathrm{BHCl}$ in the heart. $\mathrm{BHCl}$ was shown to attenuate diabetic myocardial fibrosis, while the other report demonstrated a role for $\mathrm{BHCl}$ in the regulation of calcium signaling and muscle contractility associated with arrhythmias $[92,93]$. The actions for $\mathrm{BHCl}$ on HDAC activity and histone acetylation are less known; only our paper has demonstrated inhibition of class I and IIb HDAC activity, in which HDACs 1, 3, 6, 8, \& 10 were inhibited by $\mathrm{BHCl}$ treatment [51]. Given these sparse findings, $\mathrm{BHCl}$ serves as an interesting candidate for future investigations regarding epigenetic actions in the heart. The poor bioavailability afforded to $\mathrm{BHCl}$ is of concern, as it is inadequately absorbed from the gastrointestinal tract [94]. However, formulations combining $\mathrm{BHCl}$ with chitosan, polymer-based phospholipid micelles or micro-emulsifying drug delivery systems has been shown to increase GI absorption [94-96], potentially limiting this confounding variable.

\section{Caffeic acid}

Caffeic acid is a polyphenol found in diverse food types but commonly associated with coffee consumption. Coffee is the most widely consumed beverage behind water, with moderate coffee consumption deemed safe and beneficial in healthy persons [97]. Unsurprisingly, a meta-analysis of prospective studies published between 1946 and 2015 demonstrated that coffee consumption is associated with a significant reduction in the risk of death after acute myocardial infarction [98]. Consistent with these findings, caffeic acid treatment prior to or after ischemia/reperfusion injury has been shown to significantly reduce myocardial infarct size in rabbits. This reduction was due in part to inhibition of p38 MAPK signaling and amelioration of myocyte apoptosis [99]. Likewise, other reports demonstrate that caffeic acid treatment attenuates pathological cardiac remodeling via inhibition of MAPK signaling [100,101]. Something else that is of interest is that the class III HDACs, Sirt1 and Sirt3 have been implicated in the cardio-protective actions for caffeic acid [101]. However, no reports have looked at the inhibitory impact of caffeic acid on the non-sirtuin HDACs in the heart. This is important, as recent reports demonstrate that caffeic acid and caffeic acid derivatives inhibit non-sirtuin HDAC activity in vitro [51, 59, 102]. Future studies examining caffeic acid HDAC inhibition as cardio-protective would be of immense interest, in part due to the widespread consumption of coffee. Additionally, delineation of HDAC activity in the blood of non-coffee and coffee drinkers could shed light into the mechanistic actions attributed to the health benefits of this beverage.

\section{Dihydromyricetin}

Dihydromyricetin is a flavanoid that can be found in Hovenia, the oriental raisin tree, and is listed as a premier anti-hangover medicine in China [103]. In the heart, dihydromyricetin has been shown 
to protect against diabetic cardiomyopathy, ischemia/reperfusion, angiotensin II-mediated cardiac remodeling, and chemotherapy-induced cardiotoxicity [104-107]. In these reports, cardioprotection was a consequence of dihydromyricetin-mediated anti-inflammatory, anti-oxidant, and anti-apoptotic actions [104, 105, 107]. To date, no reports have studied a role for dihydromyricetin in the regulation of HDAC inhibitor mediated cardiac regulation. Moreover, only one published report has shown that dihydromyricetin inhibits non-sirtuin HDAC activity [51]. Studies are currently underway in our lab to determine whether the cardio-protective actions for dihydromyricetin is dependent on inhibition of HDACs.

\section{Emodin}

Emodin is an anthraquinone found in the resin from rhubarb, buckthorn, and Japanese knotweed and has traditionally been used in Chinese herbal medicines as a laxative [108]. However, recent efforts have been made in studying the cardio-protective effects of emodin, with this compound emerging as a potential therapeutic in various inflammatory diseases [108]. Emodin has been shown to attenuate cardiac remodeling and improve systolic function in a rat model of diabetic cardiomyopathy [109]. Likewise, emodin was reported to significantly inhibit myocardial cell apoptosis and inflammation in a mouse model of acute myocardial infarction; these effects were mediated in part via suppression of inflammatory signaling and gene expression [110]. Lastly, emodin has been reported to protect the heart against ischemia/reperfusion injury, in part through mitochondrial anti-oxidant actions $[111,112]$. While these papers demonstrate cardio-protection via emodin-dependent inhibition of inflammation and oxidative damage, HDACs have been implicated as regulators of these systems [7, 113-115]. However, only a couple of papers have implicated emodin as an HDAC inhibitor and none have linked emodin-mediated cardio-protection to these epigenetic actions regarding HDAC activity [51, 61]. Recent and unpublished findings from our lab demonstrate that emodin potently inhibits HDAC activity and increases histone acetylation in cardiac myocytes. Moreover, these changes in histone modification correlate with attenuation of pathological cardiac hypertrophy (Unpublished data). Thus, we speculate there is significant potential for emodin as a medicinal herb to prevent or treat heart disease; intensive studies are underway to test this postulate.

\section{Epigallocatechin Gallate (EGCG)}

Green tea has been considered a health-promoting beverage since ancient times. Epigallocatechin gallate (EGCG) is the most abundant catechin in green tea and has been extensively studied for its anti-carcinogenic, anti-inflammatory, and anti-oxidant properties, in addition to its cardiovascular and metabolic health benefits [116]. In the heart, EGCG has been shown to block cardiac remodeling and restore cardiac function in diabetic rats [117, 118] and aging mice [67], as well as protect the heart from chemo-therapeutic cardiotoxicity [119-121], isoproterenol-induced myocardial infarction [122], and ischemia/reperfusion injury [123, 124]. Significantly, recent findings have shown that EGCG treatment improved age-related diastolic dysfunction, in part through the inhibition of HDACs 1 and 3 [67]. EGCG-mediated inhibition of HDAC activity corresponded to decreased HDAC binding and increased histone acetylation at the cardiac troponin I promoter, which led to increased troponin I expression [67]. Cardiac troponins play an essential role in cardiac contraction and relaxation, suggesting that EGCG-mediated restoration of troponin 
I expression in old mice contributed to prevention of diastolic dysfunction. While this was the first study to explore EGCG's inhibitory actions of HDACs in the heart, subsequent studies are needed to confirm if EGCG-mediated cardio-protection results from epigenetic regulation of gene expression.

\section{Gossypol}

Gossypol is a polyphenol commonly found in the seed, roots and stem of the cotton plant. While gossypol provides the yellow pigment associated with cottonseed oil, it functions to minimize insect predation by promoting insect infertility [125]. This attribute has led to studies using gossypol as a male contraceptive in China and Africa [125]. Unfortunately, gossypol toxicosis has been commonly reported in cattle, goats, pigs, birds, and dogs [126-131]. Something that is of additional concern is how gossypol has been reported to cause cardio-toxicity and heart failure in dogs [128]. Unsurprisingly, unpublished findings from our lab noted cardiac myocyte death in response to gossypol treatments, with no visible inhibition of cardiac myocyte size noted at nonapoptotic doses $(<1 \mu \mathrm{M})$. These data would suggest poor therapeutic range for this compound, while infertility and toxicology studies would contraindicate this food bioactive for the prevention or treatment of heart failure.

\section{Hematoxylin}

Hematoxylin is a compound extracted from the heartwood of the Longwood tree and is a common component of hematoxylin and eosin staining used in histology labs throughout the world [132]. While hematoxylin is extensively used in the cardiac field regarding its applications in histology, we have yet to find an article that looks at the cardio-protective actions for this compound. Moreover, only one published report demonstrates that hematoxylin inhibits HDAC activity [51]. Consequently, future investigations examining hematoxylin in the heart would be of significant interest and provide new insights into a commonly used histological reagent.

\section{Indirubin}

Indirubin can be found in Danggui Lonhhui Wan, a traditional Chinese medicine that showed promising results in the 1980's for the treatment of chronic myelocytic leukemia [133]. Subsequent studies demonstrated anti-proliferative actions of indirubin in addition to indirubin-based compounds such as indirubin-3'-monoxime through inhibition of glycogen synthase kinase-3 $\beta$ (GSK-3 $\beta$ ) [133]. These small molecule indirubin-based compounds have since been shown to protect the heart in rodent models of hyperlipidemia, hypertension, and diabetes [134-137]. Molecular studies have suggested that indirubin-mediated inhibition of GSK-3 $\beta$ contributes to cardioprotection [134-137]. Something else of interest is that HDACs have been previously linked to regulation of GSK-3 $\beta$ in the heart, in which pharmacological or genetic inhibition of HDAC2 resulted in modulation of GSK-3 $\beta$ activity in a manner that attenuated cardiac hypertrophy [138]. As indirubin has been shown to inhibit HDAC activity [51], these results suggest that cardioprotective actions of indirubin are HDAC-dependent.

\section{Kaempferol}

Kaempferol is a flavanoid that can be found in delphinium (perennial flowering plants), witchhazel, grapefruit, tea, broccoli, apples, strawberries, and beans [139]. Kaempferol contributes 
significantly to flavanoid intake in humans (25-33\% of mean flavanols intake), with U.S. consumption estimated at 6-10 milligrams per day [140]. This is important, as increased kaempferol intake has been correlated to decreased ischemic heart disease mortality [141]. Indeed, kaempferol has been shown to ameliorate myocardial injury in diabetic rats [142], attenuate cardiac hypertrophy, and improve cardiac function in mice subjected to aortic banding [143] in addition to protecting against myocardial ischemia/reperfusion injury [144-146]. Similar to the compounds noted above, kaempferol-mediated protection was dependent on the inhibition of intracellular signaling cascades including GSK-3 $\beta$ and MAPKs [142, 143, 145]. As mentioned previously, inhibition of HDAC activity has been reported to regulate phosphorylation of these critical signaling molecules [28, 138]. This is important as recent reports demonstrate that kaempferol acts as a pan-HDAC inhibitor, in which decreased activity was observed for HDACs 1-11 [51, 68]. Concomitant with HDAC inhibition, hyperacetylation of histone complex $\mathrm{H} 3$ was further observed [68]. Altogether, these findings suggest that kaempferol protects the heart via HDAC-dependent mechanisms. Current studies are underway to investigate this hypothesis.

\section{Luteolin}

Luteolin belongs to a group of compounds called flavones and can be found in fruits and vegetables including celery, parsley, broccoli, onion leaves, carrots, peppers, cabbages, apple skins, and chrysanthemum flowers [147]. Luteolin has traditionally been used in Chinese medicine for the treatment of hypertension, inflammation, and cancer [147]. While dietary intakes of luteolin remain low [141], there has been at least one study that associated luteolin intake with decreased stroke incidence [148], although others reported no association [149]. In the heart, luteolin was found to improve cardiac dysfunction in heart failure rats, in addition to enhancing cardiac contractility during ischemia/reperfusion injury. These actions were likely mediated via enhancement of sarcoplasmic reticulum $\mathrm{Ca}^{2+}$-ATPase 2a (SERCA2a) [150, 151]. SERCA2a regulates excitation/contraction coupling and its role in heart failure has been extensively studied, in which SERCA2a expression and activity is decreased with cardiac failure [152]. Recently, sumoylation of SERCA2a by small ubiquitin-related modifier 1 (Sumo1) was shown to act as a key regulator of SERCA2a expression and activity, in which Sumo1 expression and SERCA2a sumoylation was decreased in heart failure patients. Sumo1 restitution by gene delivery was sufficient to restore SERCA2a expression and improve cardiac function [153]. These findings are interesting, as others have shown that inhibition of HDACs can increase sumoylation of high molecular weight proteins in cardiac myocytes; SERCA2a is a $110 \mathrm{kDa}$ protein [154]. Moreover, recent reports have shown that luteolin inhibits HDAC activity and increases histone acetylation [51, 69], suggesting that luteolin-mediated changes in SERCA2a sumoylation, with stability therefore being mediated in part through HDAC activity.

\section{Morin Hydrate}

Morin is a flavonol commonly found in the branches of white mulberry, osage orange, almond, fig, mill, old fustic, and other members of the Moraceae family [155]. Morin has been shown to possess free radical scavenging, anti-inflammatory, anti-apoptotic, and anticancer properties [155]. In the heart, morin acts as a free radical scavenger to ameliorate isoproterenol-induced myocardial infarction in rats [156]. Morin has also been shown to attenuate obesity-mediated 
hypertension in high fat fed rats as well as ameliorate hypertension in salt sensitive rats; these effects are likely mediated through reductions in oxidization of low-density lipoprotein (LDL) [157-159]. The potent anti-oxidant properties of morin are due to its ability to scavenge free radicals, increase expression of xanthine oxidase as well as chelate metal ions that contribute to oxyradical formation [160]. While we reported that morin inhibits HDAC acitivity [51], we did not show that inhibition was via direct interaction with the catalytic domain. We could postulate that morin instead chelates zinc ions, limiting zinc-dependent catalytic activity of HDACs; this may contribute to its cardio-protective actions.

\section{Myricetin}

Myricetin is a common plant-derived flavonol found in berries, vegetables, teas, and wines [161]. Moreover, myricetin is structurally related to several well-known phenolic compounds including quercetin, morin hydrate, and kaempferol. Accordingly, myricetin has been used for its strong antioxidant, anticancer, antidiabetic, and anti-inflammatory properties [161]. Unlike kaempferol and quercetin, which are the largest contributors to flavonoid content in the American diet, myricetin only contributes 4\% [140]. Despite its lower abundance in the diet, myricetin has shown promise as an anti-hypertensive therapeutic in high salt sensitive rats in addition to in fructose hypertensive rats [162, 163]. Furthermore, myricetin has been shown to protect the heart against ischemia/reperfusion injury [164, 165] and isoproterenol-induced myocardial infarction [166]. While these effects were mediated in part through the anti-oxidant actions of myricetin $[165,166]$, others noted direct inhibition of signal transducer and activator of transcription 1 (STAT1) activity [164]. Unfortunately, few studies have probed into the mechanistic actions of myricetin in the heart. To date, only one report has shown that myricetin inhibits HDAC activity [51], with no studies looking at the role for myricetin-mediated HDAC inhibition in the heart. These studies are currently underway.

\section{Myricitrin}

Myricitrin is a myricetin glycoside that can be found in black walnut or the root bark of the Bayberry tree. Unlike myricetin, little is known regarding myricitrin in the heart. To date, only three studies have examined cardio-protective actions for myricitrin [167-169]. The first showed that myricitrin attenuated $\mathrm{H} 9 \mathrm{c} 2$ rat cardiac myoblast apoptosis under hyperglycemic conditions. Under hyperglycemic conditions, myricitrin decreased apoptotic gene expression and increased anti-oxidant protein expression in part through AKT-NF-E2-related factor 2 (Nrf2)-mediated signaling [168]. The second paper reported cardio-protection of myricitrin in a rat model of doxorubicin-induced cardiotoxicity via maintenance of mitochondrial membrane potential and reduced oxidative stress and apoptosis [169]. The third report demonstrated that myricitrin protected the heart against diabetic cardiomyopathy. Similar to their previous report, Zhang et al. [167] showed that cardioprotection was mediated through inhibition of Nrf2 via regulation of AKT and ERK phosphorylation. Our current findings that myricitrin inhibits HDAC activity [51] may shed new light into the cardio-protective actions of this compound, particularly given the known role for HDAC inhibitors in the regulation of AKT and ERK phosphorylation [28, 170]. 


\section{Palmatine Chloride}

Rhizoma coptidis (RC) is the dried rhizome of medicinal plants from the family Ranunculaceae, [171] and has been used in traditional Chinese medicine dating back to $2800 \mathrm{BC}$ in the Eastern Han Dynasty [172] for its antibacterial, antiviral, anti-inflammatory, anti-hyperglycemic, and hypo-lipidemic activities [173]. Today, RC is used in herbal medicine for the treatment of obesity, diabetes mellitus, hyperlipidemia, hyperglycemia, and lipid metabolism disorders [174]. The major bioactive constituents of RC include berberine, coptisine, palmatine, epiberberine, jatorrhizine, and magnoflorine [174]. Of these, palmatine is a protoberberine class of isoquinoline alkaloids that has been recently shown to ameliorate ischemia/reperfusion-induced acute myocardial injury [175]. These effects were mediated in part via increased anti-oxidant protein expression and reduction of inflammation [175]. As noted previously, HDAC inhibitors have been shown to inhibit oxidative stress and inflammation via regulation of gene expression [7, 113-115]. As our lab has shown that palmatine inhibits HDAC activity in cardiac tissue [51], these findings suggest potential unexplored actions for palmatine chloride in the epigenetic regulation of the heart.

\section{Quercein Dihydrate}

Quercetin is the largest contributor to flavanol intake in the U.S., comprising 70-75\% mean flavone intake or approximately 20-22 milligrams per day. Much of this comes from consumption of onions, teas, berries, and apples [140]. Similar to kaempferol, increased quercetin consumption correlated to decreased death due to ischemic heart disease [141]. Of the compounds from our HDAC inhibitor screen, quercetin is the most widely studied in the heart. Unsurprisingly, quercetin protects the heart against heat stroke-induced injury [176], age-dependent ischemia/reperfusion injury [177], isoproterenol-induced cardiac injury [178], pathological cardiac remodeling in response to aortic constriction [179], diabetic cardiomyopathy [180], and myocardial infarction [181]. Of significance, two independent randomized controlled trials, in which healthy, lean, obese, or early stage hypertension patients were assigned placebo or quercetin showed significant reductions in systolic and diastolic blood pressure in patient's receiving quercetin supplementation $[182,183]$. These data demonstrate direct human impact for quercetin in cardiovascular protection. However, what is lesser known regarding the role of quercetin on HDAC activity. Of the zinc dependent HDACs, one report demonstrated that quercetin inhibited the class I HDAC and HDAC8 [184]. More recent findings from our lab demonstrate that quercetin dihydrate acts as a pan-HDAC inhibitor that can target HDACs 1-10 for inhibition while increasing lysine acetylation [51]. As a next step, it would be interesting to delineate if HDAC activity was inhibited in subjects supplemented with quercetin and whether or not quercetin-mediated HDAC inhibition contributed to reduction in systolic and diastolic blood pressure.

\section{Whole and Functional Foods}

While most of this review has focused on individual bioactive food compounds in the regulation of epigenetic heart disease, it is important to note that these compounds are packaged in combination within fruits and vegetables that we consume and/or added to foods 'functional foods' to improve or maintain health. As a result, it is increasingly imperative that we understand how whole and functional foods solicit epigenetic changes to regulate optimal health and prevent 
disease. Indeed, these studies are currently underway. For instance, grape powder extract was recently shown to improve blood lipid profiles in mice, in part, via inhibition of HDACs 2 and 3 and thus induction of peroxisome proliferator-activated receptor alpha (PPAR $\alpha$ ), a critical regulator of hepatic lipid metabolism [49]. Thus, consumption of procyanidin-rich grapes, grape juice, or wine has the potential to elicit epigenetic changes in a manner consistent with heart health [185]. Similarly, functional foods such as peal millet, a cereal enriched with flavanoids and phenolic acids, has been inversely correlated to mortality from coronary heart disease and heart attacks [186]. Investigators in this report, further identified the common flavanoids and phenolic acids present in several varieties of pearl millet, in which luteolin was commonly present [186]. These data would suggest that pearl millet potentially elicits heart healthy benefits in part through epigenetic regulation of DNA accessibility and therefore gene expression. While significant work is still required to better understand the epigenetic impact for whole and functional foods on optimal human health and disease prevention, current studies have begun highlighting the scientific evidence which gives validity to the phrase "you are what you eat."

\section{CONCLUSION}

HDAC inhibitor therapy is efficacious and prevalent in pharmacology (e.g. Vorinostat, Romidepsin, and Valproic Acid), although FDA approval is predominantly for the treatment of cancer. Vorinostat (SAHA) poses a potential option for the treatment of human HF partially due to its therapeutic efficacy in rabbit ischemia/reperfusion, which established a large animal proofof-concept and set the stage for future clinical trials in humans [8]. Additionally, SAHA is FDA approved, making human HF trials feasible within a shorter period of time [187].

While drugs like SAHA require FDA approval, bioactive food compounds such as sulforaphane have less FDA oversight due to the 1994 DSHEA act. Thus, bioactive HDAC inhibitors have the potential to see human studies more readily than current HDAC inhibitor therapies examined. Sulforaphane is an HDAC inhibitor found in broccoli that has been shown to increase histone acetylation from test tube to man [44]. While sulforaphane demonstrated proofof-principle (i.e. HDAC inhibitor) in healthy persons, it should be noted that these studies were acute $(<24 \mathrm{hrs})$ and indices of heart function were not examined. However, these data suggest that sulforaphane passed the intestinal epithelium as HDAC activity was inhibited in the blood. Future studies examining sulforaphane supplementation or broccoli feeding in HF patients would be of particular interest; blood diagnostics examining circulating atrial natriuretic factor (ANF), a classical HF biomarker, in addition to echocardiography for cardiac wall thickness and function could be measured as functional readouts for patient improvement.

From our original compound screen [51], EGCG and quercetin are two food bioactives that also hold promise for heart failure treatment. EGCG has reportedly been shown to protect the heart from dysfunction and was recently shown to inhibit HDAC activity in aging mice $[67,117,123$, 124]. As green tea is highly consumed for its health promoting benefits, it would be interesting to examine HDAC activity in the blood of healthy, lean, and obese individuals with and without green tea consumption. These data would open the door for future investigations into green tea/EGCG supplementation for heart promoting benefits that are dependent on epigenetic regulation. Quercetin supplementation has already been shown to reduce hypertension in lean and obese patients, suggesting cardiovascular protection $[182,183]$. As a next step, it would be interesting to 
examine changes in HDAC activity and histone acetylation in patients supplemented with quercetin to note if hemodynamic improvements result from epigenetic actions of this food bioactive.

To conclude, nutri-epigenetics is a rapidly emerging field that has increased our knowledge concerning diet-gene interactions for health and disease. Our group and others are delineating bioactive HDAC inhibitors in fruits, vegetables, herbs, and food stuffs at an increasing rate. We propose the idea that many bioactive compounds act as epigenetic modifiers, in particular HDAC inhibitors, given the abundance of identified and unknown polyphenols and flavonoids in a variety of plants, herbs, and food stuffs. This suggests that food bioactives can work individually or cooperatively in the regulation of human health and disease. Lastly, bioactive food compound HDAC inhibitors offer exciting opportunities as therapeutics for the prevention or treatment of HF.

List of Abbreviations: HF, Heart failure; HDAC, histone deacetylase; ACEi, angiotensin converting enzyme inhibitors; HAT, histone acetyltransferase; NAD+ nicotinamide adenine dinucleotide; PKC, protein kinase C; MAPK, mitogen-activated protein kinase; BHCL, Berberine Hydrochloride; EGCG, Epigallocatechin Gallate; GSK-3 $\beta$, glycogen synthase kinase-3 $\beta$; SERCA2a , sarcoplasmic reticulum $\mathrm{Ca}^{2+}$-ATPase 2a-; Sumo1, small ubiquitin-related modifier 1; LDL, low-density lipoprotein; STAT1, signal transducer and activator of transcription 1; Nrf2, AKT-NF-E2-related factor 2; RC, Rhizoma coptidis.

Author Contributions: All authors contributed to this review

Competing Interests: The authors declare no financial or any other conflicts of interest.

Acknowledgements and Funding: This work is supported by the USDA National Institute of Food and Agriculture (Hatch-NEV00727) and the Dennis Meiss \& Janet Ralston Fund for Nutriepigenetic Research to B.S.F.

\section{REFERENCES}

1. Mozaffarian D, Benjamin EJ, Go AS, Arnett DK, Blaha MJ, Cushman M, de Ferranti S, Despres JP, Fullerton HJ, Howard VJ, et al: Heart disease and stroke statistics--2015 update: a report from the American Heart Association. Circulation 2015, 131:e29-322.

2. Benjamin EJ, Blaha MJ, Chiuve SE, Cushman M, Das SR, Deo R, de Ferranti SD, Floyd J, Fornage M, Gillespie C, et al: Heart Disease and Stroke Statistics-2017 Update: A Report From the American Heart Association. Circulation 2017, 135:e146-e603.

3. McKinsey TA: Therapeutic potential for HDAC inhibitors in the heart. Annu Rev Pharmacol Toxicol 2012, 52:303-319.

4. Aurigemma GP, de Simone G, Fitzgibbons TP: Cardiac remodeling in obesity. Circ Cardiovasc Imaging 2013, 6:142-152.

5. Mann DL, Bristow MR: Mechanisms and models in heart failure: the biomechanical model and beyond. Circulation 2005, 111:2837-2849. 
6. McKinsey TA: Isoform-selective HDAC inhibitors: closing in on translational medicine for the heart. J Mol Cell Cardiol 2011, 51:491-496.

7. Ferguson BS, McKinsey TA: Non-sirtuin histone deacetylases in the control of cardiac aging. J Mol Cell Cardiol 2015, 83:14-20.

8. Xie M, Kong Y, Tan W, May H, Battiprolu PK, Pedrozo Z, Wang ZV, Morales C, Luo X, Cho G, et al: Histone deacetylase inhibition blunts ischemia/reperfusion injury by inducing cardiomyocyte autophagy. Circulation 2014, 129:1139-1151.

9. Kong Y, Tannous P, Lu G, Berenji K, Rothermel BA, Olson EN, Hill JA: Suppression of class I and II histone deacetylases blunts pressure-overload cardiac hypertrophy. Circulation 2006, 113:2579-2588.

10. Cao DJ, Wang ZV, Battiprolu PK, Jiang N, Morales CR, Kong Y, Rothermel BA, Gillette TG, Hill JA: Histone deacetylase (HDAC) inhibitors attenuate cardiac hypertrophy by suppressing autophagy. Proc Natl Acad Sci U S A 2011, 108:4123-4128.

11. Berry JM, Cao DJ, Rothermel BA, Hill JA: Histone deacetylase inhibition in the treatment of heart disease. Expert Opin Drug Saf 2008, 7:53-67.

12. Yang XJ, Seto E: HATs and HDACs: from structure, function and regulation to novel strategies for therapy and prevention. Oncogene 2007, 26:5310-5318.

13. Gregoretti IV, Lee YM, Goodson HV: Molecular evolution of the histone deacetylase family: functional implications of phylogenetic analysis. J Mol Biol 2004, 338:17-31.

14. Bradner JE, West N, Grachan ML, Greenberg EF, Haggarty SJ, Warnow T, Mazitschek R: Chemical phylogenetics of histone deacetylases. Nat Chem Biol 2010, 6:238-243.

15. Marks PA, Breslow R: Dimethyl sulfoxide to vorinostat: development of this histone deacetylase inhibitor as an anticancer drug. Nat Biotechnol 2007, 25:84-90.

16. Iyer SP, Foss FF: Romidepsin for the Treatment of Peripheral T-Cell Lymphoma. Oncologist 2015, 20:1084-1091.

17. Terbach N, Williams RS: Structure-function studies for the panacea, valproic acid. Biochem Soc Trans 2009, 37:1126-1132.

18. Wagner FF, Wesmall yi UM, Lewis MC, Holson EB: Small molecule inhibitors of zincdependent histone deacetylases. Neurotherapeutics 2013, 10:589-604.

19. Wagner FF, Weiwer M, Steinbacher S, Schomburg A, Reinemer P, Gale JP, Campbell AJ, Fisher SL, Zhao WN, Reis SA, et al: Kinetic and structural insights into the binding of histone deacetylase 1 and 2 (HDAC1, 2) inhibitors. Bioorg Med Chem 2016, 24:4008-4015.

20. Haggarty SJ, Koeller KM, Wong JC, Grozinger CM, Schreiber SL: Domain-selective smallmolecule inhibitor of histone deacetylase 6 (HDAC6)-mediated tubulin deacetylation. Proc Natl Acad Sci U S A 2003, 100:4389-4394.

21. Stratton MS, McKinsey TA: Epigenetic regulation of cardiac fibrosis. J Mol Cell Cardiol 2016, 92:206-213.

22. Schuetze KB, McKinsey TA, Long CS: Targeting cardiac fibroblasts to treat fibrosis of the heart: focus on HDACs. J Mol Cell Cardiol 2014, 70:100-107.

23. Antos CL, McKinsey TA, Dreitz M, Hollingsworth LM, Zhang CL, Schreiber K, Rindt H, Gorczynski RJ, Olson EN: Dose-dependent blockade to cardiomyocyte hypertrophy by histone deacetylase inhibitors. J Biol Chem 2003, 278:28930-28937.

24. Kee HJ, Sohn IS, Nam KI, Park JE, Qian YR, Yin Z, Ahn Y, Jeong MH, Bang YJ, Kim N, et al: Inhibition of histone deacetylation blocks cardiac hypertrophy induced by angiotensin II infusion and aortic banding. Circulation 2006, 113:51-59. 
25. Kook H, Lepore JJ, Gitler AD, Lu MM, Wing-Man Yung W, Mackay J, Zhou R, Ferrari V, Gruber P, Epstein JA: Cardiac hypertrophy and histone deacetylase-dependent transcriptional repression mediated by the atypical homeodomain protein Hop. J Clin Invest 2003, 112:863-871.

26. Kao YH, Liou JP, Chung CC, Lien GS, Kuo CC, Chen SA, Chen YJ: Histone deacetylase inhibition improved cardiac functions with direct antifibrotic activity in heart failure. Int J Cardiol 2013, 168:4178-4183.

27. Williams SM, Golden-Mason L, Ferguson BS, Schuetze KB, Cavasin MA, Demos-Davies K, Yeager ME, Stenmark KR, McKinsey TA: Class I HDACs regulate angiotensin IIdependent cardiac fibrosis via fibroblasts and circulating fibrocytes. J Mol Cell Cardiol 2014, 67:112-125.

28. Ferguson BS, Harrison BC, Jeong MY, Reid BG, Wempe MF, Wagner FF, Holson EB, McKinsey TA: Signal-dependent repression of DUSP5 by class I HDACs controls nuclear ERK activity and cardiomyocyte hypertrophy. Proc Natl Acad Sci U S A 2013, 110:98069811.

29. Nural-Guvener HF, Zakharova L, Nimlos J, Popovic S, Mastroeni D, Gaballa MA: HDAC class I inhibitor, Mocetinostat, reverses cardiac fibrosis in heart failure and diminishes CD90+ cardiac myofibroblast activation. Fibrogenesis Tissue Repair 2014, 7:10.

30. Nural-Guvener H, Zakharova L, Feehery L, Sljukic S, Gaballa M: Anti-Fibrotic Effects of Class I HDAC Inhibitor, Mocetinostat Is Associated with IL-6/Stat3 Signaling in Ischemic Heart Failure. Int J Mol Sci 2015, 16:11482-11499.

31. Lee TM, Lin MS, Chang NC: Inhibition of histone deacetylase on ventricular remodeling in infarcted rats. Am J Physiol Heart Circ Physiol 2007, 293:H968-977.

32. Demos-Davies KM, Ferguson BS, Cavasin MA, Mahaffey JH, Williams SM, Spiltoir JI, Schuetze KB, Horn TR, Chen B, Ferrara C, et al: HDAC6 contributes to pathological responses of heart and skeletal muscle to chronic angiotensin-II signaling. Am J Physiol Heart Circ Physiol 2014, 307:H252-258.

33. McLendon PM, Ferguson BS, Osinska H, Bhuiyan MS, James J, McKinsey TA, Robbins J: Tubulin hyperacetylation is adaptive in cardiac proteotoxicity by promoting autophagy. Proc Natl Acad Sci U S A 2014, 111:E5178-5186.

34. Shukla S, Meeran SM, Katiyar SK: Epigenetic regulation by selected dietary phytochemicals in cancer chemoprevention. Cancer Lett 2014, 355:9-17.

35. Rein MJ, Renouf M, Cruz-Hernandez C, Actis-Goretta L, Thakkar SK, da Silva Pinto M: Bioavailability of bioactive food compounds: a challenging journey to bioefficacy. $\mathrm{Br} \mathrm{J}$ Clin Pharmacol 2013, 75:588-602.

36. Suleria HA, Osborne S, Masci P, Gobe G: Marine-Based Nutraceuticals: An Innovative Trend in the Food and Supplement Industries. Mar Drugs 2015, 13:6336-6351.

37. Liu RH: Health-promoting components of fruits and vegetables in the diet. Adv Nutr 2013, 4:384S-392S.

38. Bassett SA, Barnett MP: The role of dietary histone deacetylases (HDACs) inhibitors in health and disease. Nutrients 2014, 6:4273-4301.

39. Kim E, Bisson WH, Lohr CV, Williams DE, Ho E, Dashwood RH, Rajendran P: Histone and Non-Histone Targets of Dietary Deacetylase Inhibitors. Curr Top Med Chem 2016, 16:714-731. 
40. Szarc vel Szic K, Ndlovu MN, Haegeman G, Vanden Berghe W: Nature or nurture: let food be your epigenetic medicine in chronic inflammatory disorders. Biochem Pharmacol 2010, 80:1816-1832.

41. Vahid F, Zand H, Nosrat-Mirshekarlou E, Najafi R, Hekmatdoost A: The role dietary of bioactive compounds on the regulation of histone acetylases and deacetylases: a review. Gene 2015, 562:8-15.

42. Chen Y, Du J, Zhao YT, Zhang L, Lv G, Zhuang S, Qin G, Zhao TC: Histone deacetylase (HDAC) inhibition improves myocardial function and prevents cardiac remodeling in diabetic mice. Cardiovasc Diabetol 2015, 14:99.

43. Chen T, Li J, Liu J, Li N, Wang S, Liu H, Zeng M, Zhang Y, Bu P: Activation of SIRT3 by resveratrol ameliorates cardiac fibrosis and improves cardiac function via the TGFbeta/Smad3 pathway. Am J Physiol Heart Circ Physiol 2015, 308:H424-434.

44. Myzak MC, Ho E, Dashwood RH: Dietary agents as histone deacetylase inhibitors. Mol Carcinog 2006, 45:443-446.

45. Morimoto T, Sunagawa Y, Kawamura T, Takaya T, Wada H, Nagasawa A, Komeda M, Fujita M, Shimatsu A, Kita T, Hasegawa K: The dietary compound curcumin inhibits p300 histone acetyltransferase activity and prevents heart failure in rats. J Clin Invest 2008, 118:868-878.

46. Wang SH, Lin PY, Chiu YC, Huang JS, Kuo YT, Wu JC, Chen CC: Curcumin-Mediated HDAC Inhibition Suppresses the DNA Damage Response and Contributes to Increased DNA Damage Sensitivity. PLoS One 2015, 10:e0134110.

47. Dashwood RH, Ho E: Dietary histone deacetylase inhibitors: from cells to mice to man. Semin Cancer Biol 2007, 17:363-369.

48. Dashwood RH: Frontiers in polyphenols and cancer prevention. J Nutr 2007, 137:267S269S.

49. Downing LE, Ferguson BS, Rodriguez K, Ricketts ML: A grape seed procyanidin extract inhibits HDAC activity leading to increased Pparalpha phosphorylation and target gene expression. Mol Nutr Food Res 2016.

50. Imran M, Saeed F, Nadeem M, Arshad MU, Ullah A, Suleria HA: Cucurmin; Anticancer and Antitumor Perspectives - A Comprehensive Review. Crit Rev Food Sci Nutr 2016:0.

51. Godoy LD, Lucas JE, Bender AJ, Romanick SS, Ferguson BS: Targeting the epigenome: Screening bioactive compounds that regulate histone deacetylase activity. Mol Nutr Food Res 2016.

52. Pandey M, Kaur P, Shukla S, Abbas A, Fu P, Gupta S: Plant flavone apigenin inhibits HDAC and remodels chromatin to induce growth arrest and apoptosis in human prostate cancer cells: in vitro and in vivo study. Mol Carcinog 2012, 51:952-962.

53. Tseng TH, Chien MH, Lin WL, Wen YC, Chow JM, Chen CK, Kuo TC, Lee WJ: Inhibition of MDA-MB-231 breast cancer cell proliferation and tumor growth by apigenin through induction of G2/M arrest and histone $\mathrm{H} 3$ acetylation-mediated p21WAF1/CIP1 expression. Environ Toxicol 2017, 32:434-444.

54. Paredes-Gonzalez X, Fuentes F, Su ZY, Kong AN: Apigenin reactivates Nrf2 anti-oxidative stress signaling in mouse skin epidermal JB6 P + cells through epigenetics modifications. AAPS J 2014, 16:727-735. 
55. Dong N, Xu B, Shi H, Tang X: Baicalein Inhibits Amadori-Glycated Albumin-Induced MCP-1 Expression in Retinal Ganglion Cells via a MicroRNA-124-Dependent Mechanism. Invest Ophthalmol Vis Sci 2015, 56:5844-5853.

56. Wang HZ, Wang HH, Huang SS, Zhao H, Cao YG, Wang GZ, Wang D, Wang ZG, Liu YH: Inhibitory effect of baicalin on collagen-induced arthritis in rats through the nuclear factorkappaB pathway. J Pharmacol Exp Ther 2014, 350:435-443.

57. Cherng CH, Lee KC, Chien CC, Chou KY, Cheng YC, Hsin ST, Lee SO, Shen CH, Tsai RY, Wong CS: Baicalin ameliorates neuropathic pain by suppressing HDAC1 expression in the spinal cord of spinal nerve ligation rats. J Formos Med Assoc 2014, 113:513-520.

58. Mu HN, Li Q, Pan CS, Liu YY, Yan L, Hu BH, Sun K, Chang X, Zhao XR, Fan JY, Han JY: Caffeic acid attenuates rat liver reperfusion injury through sirtuin 3-dependent regulation of mitochondrial respiratory chain. Free Radic Biol Med 2015, 85:237-249.

59. Bora-Tatar G, Dayangac-Erden D, Demir AS, Dalkara S, Yelekci K, Erdem-Yurter H: Molecular modifications on carboxylic acid derivatives as potent histone deacetylase inhibitors: Activity and docking studies. Bioorg Med Chem 2009, 17:5219-5228.

60. Yang T, Wang J, Pang Y, Dang X, Ren H, Liu Y, Chen M, Shang D: Emodin suppresses silica-induced lung fibrosis by promoting Sirt1 signaling via direct contact. Mol Med Rep 2016, 14:4643-4649.

61. Ha MK, Song YH, Jeong SJ, Lee HJ, Jung JH, Kim B, Song HS, Huh JE, Kim SH: Emodin inhibits proinflammatory responses and inactivates histone deacetylase 1 in hypoxic rheumatoid synoviocytes. Biol Pharm Bull 2011, 34:1432-1437.

62. Nandakumar V, Vaid M, Katiyar SK: (-)-Epigallocatechin-3-gallate reactivates silenced tumor suppressor genes, Cip1/p21 and p16INK4a, by reducing DNA methylation and increasing histones acetylation in human skin cancer cells. Carcinogenesis 2011, 32:537544.

63. Choudhury SR, Balasubramanian S, Chew YC, Han B, Marquez VE, Eckert RL: (-)Epigallocatechin-3-gallate and DZNep reduce polycomb protein level via a proteasomedependent mechanism in skin cancer cells. Carcinogenesis 2011, 32:1525-1532.

64. Hu Q, Chang X, Yan R, Rong C, Yang C, Cheng S, Gu X, Yao H, Hou X, Mo Y, et al: (-)Epigallocatechin-3-gallate induces cancer cell apoptosis via acetylation of amyloid precursor protein. Med Oncol 2015, 32:390.

65. Thakur VS, Gupta K, Gupta S: Green tea polyphenols increase p53 transcriptional activity and acetylation by suppressing class I histone deacetylases. Int J Oncol 2012, 41:353-361.

66. Deb G, Thakur VS, Limaye AM, Gupta S: Epigenetic induction of tissue inhibitor of matrix metalloproteinase-3 by green tea polyphenols in breast cancer cells. Mol Carcinog 2015, 54:485-499.

67. Pan B, Quan J, Liu L, Xu Z, Zhu J, Huang X, Tian J: Epigallocatechin gallate reverses cTnIlow expression-induced age-related heart diastolic dysfunction through histone acetylation modification. J Cell Mol Med 2017.

68. Berger A, Venturelli S, Kallnischkies M, Bocker A, Busch C, Weiland T, Noor S, Leischner C, Weiss TS, Lauer UM, et al: Kaempferol, a new nutrition-derived pan-inhibitor of human histone deacetylases. J Nutr Biochem 2013, 24:977-985.

69. Attoub S, Hassan AH, Vanhoecke B, Iratni R, Takahashi T, Gaben AM, Bracke M, Awad S, John A, Kamalboor HA, et al: Inhibition of cell survival, invasion, tumor growth and histone 
deacetylase activity by the dietary flavonoid luteolin in human epithelioid cancer cells. Eur J Pharmacol 2011, 651:18-25.

70. Hong KS, Park JI, Kim MJ, Kim HB, Lee JW, Dao TT, Oh WK, Kang CD, Kim SH: Involvement of SIRT1 in hypoxic down-regulation of c-Myc and beta-catenin and hypoxic preconditioning effect of polyphenols. Toxicol Appl Pharmacol 2012, 259:210-218.

71. Ganesan S, Faris AN, Comstock AT, Chattoraj SS, Chattoraj A, Burgess JR, Curtis JL, Martinez FJ, Zick S, Hershenson MB, Sajjan US: Quercetin prevents progression of disease in elastase/LPS-exposed mice by negatively regulating MMP expression. Respir Res 2010, 11:131.

72. Mahajan UB, Chandrayan G, Patil CR, Arya DS, Suchal K, Agrawal YO, Ojha S, Goyal SN: The Protective Effect of Apigenin on Myocardial Injury in Diabetic Rats mediating Activation of the PPAR-gamma Pathway. Int J Mol Sci 2017, 18.

73. Zhu Y, Di S, Hu W, Feng Y, Zhou Q, Gong B, Tang X, Liu J, Zhang W, Xi M, et al: A new flavonoid glycoside (APG) isolated from Clematis tangutica attenuates myocardial ischemia/reperfusion injury via activating PKCepsilon signaling. Biochim Biophys Acta 2017, 1863:701-711.

74. Yang $\mathrm{X}$, Yang $\mathrm{J}$, Hu J, Li X, Zhang X, Li Z: Apigenin attenuates myocardial ischemia/reperfusion injury via the inactivation of $\mathrm{p} 38$ mitogenactivated protein kinase. Mol Med Rep 2015, 12:6873-6878.

75. Hu J, Li Z, Xu LT, Sun AJ, Fu XY, Zhang L, Jing LL, Lu AD, Dong YF, Jia ZP: Protective effect of apigenin on ischemia/reperfusion injury of the isolated rat heart. Cardiovasc Toxicol 2015, 15:241-249.

76. Tseng TH, Chien MH, Lin WL, Wen YC, Chow JM, Chen CK, Kuo TC, Lee WJ: Inhibition of MDA-MB-231 breast cancer cell proliferation and tumor growth by apigenin through induction of G2/M arrest and histone $\mathrm{H} 3$ acetylation-mediated p21WAF1/CIP1 expression. Environ Toxicol 2016.

77. Arango D, Diosa-Toro M, Rojas-Hernandez LS, Cooperstone JL, Schwartz SJ, Mo X, Jiang J, Schmittgen TD, Doseff AI: Dietary apigenin reduces LPS-induced expression of miR-155 restoring immune balance during inflammation. Mol Nutr Food Res 2015, 59:763-772.

78. Shimizu I: Sho-saiko-to: Japanese herbal medicine for protection against hepatic fibrosis and carcinoma. J Gastroenterol Hepatol 2000, 15 Suppl:D84-90.

79. Kumar M, Kasala ER, Bodduluru LN, Dahiya V, Lahkar M: Baicalein protects isoproterenol induced myocardial ischemic injury in male Wistar rats by mitigating oxidative stress and inflammation. Inflamm Res 2016, 65:613-622.

80. Wang AW, Song L, Miao J, Wang HX, Tian C, Jiang X, Han QY, Yu L, Liu Y, Du J, et al: Baicalein attenuates angiotensin II-induced cardiac remodeling via inhibition of AKT/mTOR, ERK1/2, NF-kappaB, and calcineurin signaling pathways in mice. Am J Hypertens 2015, 28:518-526.

81. Chen HM, Hsu JH, Liou SF, Chen TJ, Chen LY, Chiu CC, Yeh JL: Baicalein, an active component of Scutellaria baicalensis Georgi, prevents lysophosphatidylcholine-induced cardiac injury by reducing reactive oxygen species production, calcium overload and apoptosis via MAPK pathways. BMC Complement Altern Med 2014, 14:233.

82. Zong J, Zhang DP, Zhou H, Bian ZY, Deng W, Dai J, Yuan Y, Gan HW, Guo HP, Tang QZ: Baicalein protects against cardiac hypertrophy through blocking MEK-ERK1/2 signaling. J Cell Biochem 2013, 114:1058-1065. 
83. Zhang Y, Liao P, Zhu M, Li W, Hu D, Guan S, Chen L: Baicalin Attenuates Cardiac Dysfunction and Myocardial Remodeling in a Chronic Pressure-Overload Mice Model. Cell Physiol Biochem 2017, 41:849-864.

84. Zhang S, Wang J, Pan J: Baicalin-loaded PEGylated lipid nanoparticles: characterization, pharmacokinetics, and protective effects on acute myocardial ischemia in rats. Drug Deliv 2016, 23:3696-3703.

85. Sun SJ, Wu XP, Song HL, Li GQ: Baicalin ameliorates isoproterenol-induced acute myocardial infarction through iNOS, inflammation, oxidative stress and P38MAPK pathway in rat. Int J Clin Exp Med 2015, 8:22063-22072.

86. Chen Z, Wang Q: Activation of PPARgamma by baicalin attenuates pulmonary hypertension in an infant rat model by suppressing HMGB1/RAGE signaling. FEBS Open Bio 2017, 7:477-484.

87. Huang X, He Y, Chen Y, Wu P, Gui D, Cai H, Chen A, Chen M, Dai C, Yao D, Wang L: Baicalin attenuates bleomycin-induced pulmonary fibrosis via adenosine A2a receptor related TGF-beta1-induced ERK1/2 signaling pathway. BMC Pulm Med 2016, 16:132.

88. Yan S, Wang Y, Liu P, Chen A, Chen M, Yao D, Xu X, Wang L, Huang X: Baicalin Attenuates Hypoxia-Induced Pulmonary Arterial Hypertension to Improve Hypoxic Cor Pulmonale by Reducing the Activity of the p38 MAPK Signaling Pathway and MMP-9. Evid Based Complement Alternat Med 2016, 2016:2546402.

89. Liu X, Gu J, Fan Y, Shi H, Jiang M: Baicalin attenuates acute myocardial infarction of rats via mediating the mitogen-activated protein kinase pathway. Biol Pharm Bull 2013, 36:988994.

90. Li L, Bao H, Wu J, Duan X, Liu B, Sun J, Gong W, Lv Y, Zhang H, Luo Q, et al: Baicalin is anti-inflammatory in cigarette smoke-induced inflammatory models in vivo and in vitro: A possible role for HDAC2 activity. Int Immunopharmacol 2012, 13:15-22.

91. Yin J, Xing H, Ye J: Efficacy of berberine in patients with type 2 diabetes mellitus. Metabolism 2008, 57:712-717.

92. Shen N, Li X, Zhou T, Bilal MU, Du N, Hu Y, Qin W, Xie Y, Wang H, Wu J, et al: Shensong Yangxin Capsule prevents diabetic myocardial fibrosis by inhibiting TGF-beta1/Smad signaling. J Ethnopharmacol 2014, 157:161-170.

93. Sun XD, Li JM, Tian LJ, Wang YP, Yu YF, Zhang KY: [Effect of berberine on slow inward ionic current in guinea pig ventricular papillary muscle]. Zhongguo Yao Li Xue Bao 1989, 10:130-134.

94. Chen W, Fan D, Meng L, Miao Y, Yang S, Weng Y, He H, Tang X: Enhancing effects of chitosan and chitosan hydrochloride on intestinal absorption of berberine in rats. Drug Dev Ind Pharm 2012, 38:104-110.

95. Shen R, Kim JJ, Yao M, Elbayoumi TA: Development and evaluation of vitamin E d-alphatocopheryl polyethylene glycol 1000 succinate-mixed polymeric phospholipid micelles of berberine as an anticancer nanopharmaceutical. Int J Nanomedicine 2016, 11:1687-1700.

96. Zhu JX, Tang D, Feng L, Zheng ZG, Wang RS, Wu AG, Duan TT, He B, Zhu Q: Development of self-microemulsifying drug delivery system for oral bioavailability enhancement of berberine hydrochloride. Drug Dev Ind Pharm 2013, 39:499-506.

97. Chrysant SG: The impact of coffee consumption on blood pressure, cardiovascular disease and diabetes mellitus. Expert Rev Cardiovasc Ther 2017, 15:151-156. 
98. Brown OI, Allgar V, Wong KY: Coffee reduces the risk of death after acute myocardial infarction: a meta-analysis. Coron Artery Dis 2016, 27:566-572.

99. Tan J, Ma Z, Han L, Du R, Zhao L, Wei X, Hou D, Johnstone BH, Farlow MR, Du Y: Caffeic acid phenethyl ester possesses potent cardioprotective effects in a rabbit model of acute myocardial ischemia-reperfusion injury. Am J Physiol Heart Circ Physiol 2005, 289:H22652271.

100. Ren J, Zhang N, Liao H, Chen S, Xu L, Li J, Yang Z, Deng W, Tang Q: Caffeic acid phenethyl ester attenuates pathological cardiac hypertrophy by regulation of MEK/ERK signaling pathway in vivo and vitro. Life Sci 2017, 181:53-61.

101. Lee SY, Ku HC, Kuo YH, Yang KC, Tu PC, Chiu HL, Su MJ: Caffeic acid ethanolamide prevents cardiac dysfunction through sirtuin dependent cardiac bioenergetics preservation. J Biomed Sci 2015, 22:80.

102. Waldecker M, Kautenburger T, Daumann H, Busch C, Schrenk D: Inhibition of histonedeacetylase activity by short-chain fatty acids and some polyphenol metabolites formed in the colon. J Nutr Biochem 2008, 19:587-593.

103. Du J, He D, Sun LN, Han T, Zhang H, Qin LP, Rahman K: Semen Hoveniae extract protects against acute alcohol-induced liver injury in mice. Pharm Biol 2010, 48:953-958.

104.Zhu H, Luo P, Fu Y, Wang J, Dai J, Shao J, Yang X, Chang L, Weng Q, Yang B, He Q: Dihydromyricetin prevents cardiotoxicity and enhances anticancer activity induced by adriamycin. Oncotarget 2015, 6:3254-3267.

105. Meng G, Yang S, Chen Y, Yao W, Zhu H, Zhang W: Attenuating effects of dihydromyricetin on angiotensin II-induced rat cardiomyocyte hypertrophy related to antioxidative activity in a NO-dependent manner. Pharm Biol 2015, 53:904-912.

106. Liu S, Ai Q, Feng K, Li Y, Liu X: The cardioprotective effect of dihydromyricetin prevents ischemia-reperfusion-induced apoptosis in vivo and in vitro via the PI3K/Akt and HIF1alpha signaling pathways. Apoptosis 2016, 21:1366-1385.

107. Wu B, Lin J, Luo J, Han D, Fan M, Guo T, Tao L, Yuan M, Yi F: Dihydromyricetin Protects against Diabetic Cardiomyopathy in Streptozotocin-Induced Diabetic Mice. Biomed Res Int 2017, 2017:3764370.

108. Monisha BA, Kumar N, Tiku AB: Emodin and Its Role in Chronic Diseases. Adv Exp Med Biol 2016, 928:47-73.

109. Wu Z, Chen Q, Ke D, Li G, Deng W: Emodin protects against diabetic cardiomyopathy by regulating the AKT/GSK-3beta signaling pathway in the rat model. Molecules 2014, 19:14782-14793.

110. Wu Y, Tu X, Lin G, Xia H, Huang H, Wan J, Cheng Z, Liu M, Chen G, Zhang H, et al: Emodin-mediated protection from acute myocardial infarction via inhibition of inflammation and apoptosis in local ischemic myocardium. Life Sci 2007, 81:1332-1338.

111. Du Y, Ko KM: Effects of pharmacological preconditioning by emodin/oleanolic acid treatment and/or ischemic preconditioning on mitochondrial antioxidant components as well as the susceptibility to ischemia-reperfusion injury in rat hearts. Mol Cell Biochem 2006, 288:135-142.

112. Du Y, Ko KM: Effects of emodin treatment on mitochondrial ATP generation capacity and antioxidant components as well as susceptibility to ischemia-reperfusion injury in rat hearts: single versus multiple doses and gender difference. Life Sci 2005, 77:2770-2782. 
113. Leus NG, Zwinderman MR, Dekker FJ: Histone deacetylase 3 (HDAC 3) as emerging drug target in NF-kappaB-mediated inflammation. Curr Opin Chem Biol 2016, 33:160-168.

114. Das Gupta K, Shakespear MR, Iyer A, Fairlie DP, Sweet MJ: Histone deacetylases in monocyte/macrophage development, activation and metabolism: refining HDAC targets for inflammatory and infectious diseases. Clin Transl Immunology 2016, 5:e62.

115. Schmitz ML, de la Vega L: New Insights into the Role of Histone Deacetylases as Coactivators of Inflammatory Gene Expression. Antioxid Redox Signal 2015, 23:85-98.

116. Wolfram S: Effects of green tea and EGCG on cardiovascular and metabolic health. J Am Coll Nutr 2007, 26:373S-388S.

117. Chen TS, Liou SY, Kuo CH, Pan LF, Yeh YL, Liou J, Padma VV, Yao CH, Kuo WW, Huang CY: Green tea EGCG enhances cardiac function restoration through expression of survival signaling in DM rats with autologous adipose tissue-derived stem cell. J Appl Physiol (1985) 2017:jap 0047102016.

118. Liu J, Tang Y, Feng Z, Liu J, Liu J, Long J: (-)-Epigallocatechin-3-gallate attenuated myocardial mitochondrial dysfunction and autophagy in diabetic Goto-Kakizaki rats. Free Radic Res 2014, 48:898-906.

119. Yao YF, Liu X, Li WJ, Shi ZW, Yan YX, Wang LF, Chen M, Xie MY: (-)-Epigallocatechin3-gallate alleviates doxorubicin-induced cardiotoxicity in sarcoma 180 tumor-bearing mice. Life Sci 2017, 180:151-159.

120. Sun TL, Liu Z, Qi ZJ, Huang YP, Gao XQ, Zhang YY: (-)-Epigallocatechin-3-gallate (EGCG) attenuates arsenic-induced cardiotoxicity in rats. Food Chem Toxicol 2016, 93:102110.

121. Saeed NM, El-Naga RN, El-Bakly WM, Abdel-Rahman HM, Salah ElDin RA, ElDemerdash E: Epigallocatechin-3-gallate pretreatment attenuates doxorubicin-induced cardiotoxicity in rats: A mechanistic study. Biochem Pharmacol 2015, 95:145-155.

122. Othman AI, Elkomy MM, El-Missiry MA, Dardor M: Epigallocatechin-3-gallate prevents cardiac apoptosis by modulating the intrinsic apoptotic pathway in isoproterenol-induced myocardial infarction. Eur J Pharmacol 2017, 794:27-36.

123. Xuan F, Jian J: Epigallocatechin gallate exerts protective effects against myocardial ischemia/reperfusion injury through the PI3K/Akt pathway-mediated inhibition of apoptosis and the restoration of the autophagic flux. Int J Mol Med 2016, 38:328-336.

124. Kim SJ, Li M, Jeong CW, Bae HB, Kwak SH, Lee SH, Lee HJ, Heo BH, Yook KB, Yoo $\mathrm{KY}$ : Epigallocatechin-3-gallate, a green tea catechin, protects the heart against regional ischemia-reperfusion injuries through activation of RISK survival pathways in rats. Arch Pharm Res 2014, 37:1079-1085.

125. Coutinho EM: Gossypol: a contraceptive for men. Contraception 2002, 65:259-263.

126. Uzal FA, Puschner B, Tahara JM, Nordhausen RW: Gossypol toxicosis in a dog consequent to ingestion of cottonseed bedding. J Vet Diagn Invest 2005, 17:626-629.

127. Smith HA: The pathology of gossypol poisoning. Am J Pathol 1957, 33:353-365.

128. Patton CS, Legendre AM, Gompf RE, Walker MA: Heart failure caused by gossypol poisoning in two dogs. J Am Vet Med Assoc 1985, 187:625-627.

129. Huo M, Gao R, Jiang L, Cui X, Duan L, Deng X, Guan S, Wei J, Soromou LW, Feng H, Chi G: Suppression of LPS-induced inflammatory responses by gossypol in RAW 264.7 cells and mouse models. Int Immunopharmacol 2013, 15:442-449. 
130. Haschek WM, Beasley VR, Buck WB, Finnell JH: Cottonseed meal (gossypol) toxicosis in a swine herd. J Am Vet Med Assoc 1989, 195:613-615.

131. East NE, Anderson M, Lowenstine LJ: Apparent gossypol-induced toxicosis in adult dairy goats. J Am Vet Med Assoc 1994, 204:642-643.

132. Cooksey C: Hematoxylin and related compounds--an annotated bibliography concerning their origin, properties, chemistry, and certain applications. Biotech Histochem 2010, 85:6582.

133. Blazevic T, Heiss EH, Atanasov AG, Breuss JM, Dirsch VM, Uhrin P: Indirubin and Indirubin Derivatives for Counteracting Proliferative Diseases. Evid Based Complement Alternat Med 2015, 2015:654098.

134. Yadav HN, Singh M, Sharma PL: Pharmacological inhibition of GSK-3beta produces late phase of cardioprotection in hyperlipidemic rat: possible involvement of HSP 72. Mol Cell Biochem 2012, 369:227-233.

135. Yadav HN, Singh M, Sharma PL: Involvement of GSK-3beta in attenuation of the cardioprotective effect of ischemic preconditioning in diabetic rat heart. Mol Cell Biochem 2010, 343:75-81.

136. Yadav HN, Singh M, Sharma PL: Modulation of the cardioprotective effect of ischemic preconditioning in hyperlipidaemic rat heart. Eur J Pharmacol 2010, 643:78-83.

137. Gonzalez Arbelaez LF, Perez Nunez IA, Mosca SM: Gsk-3beta inhibitors mimic the cardioprotection mediated by ischemic pre- and postconditioning in hypertensive rats. Biomed Res Int 2013, 2013:317456.

138. Trivedi CM, Luo Y, Yin Z, Zhang M, Zhu W, Wang T, Floss T, Goettlicher M, Noppinger PR, Wurst W, et al: Hdac2 regulates the cardiac hypertrophic response by modulating Gsk3 beta activity. Nat Med 2007, 13:324-331.

139. Somerset SM, Johannot L: Dietary flavonoid sources in Australian adults. Nutr Cancer 2008, 60:442-449.

140. Sampson L, Rimm E, Hollman PC, de Vries JH, Katan MB: Flavonol and flavone intakes in US health professionals. J Am Diet Assoc 2002, 102:1414-1420.

141. Knekt P, Kumpulainen J, Jarvinen R, Rissanen H, Heliovaara M, Reunanen A, Hakulinen T, Aromaa A: Flavonoid intake and risk of chronic diseases. Am J Clin Nutr 2002, 76:560-568.

142. Suchal K, Malik S, Khan SI, Malhotra RK, Goyal SN, Bhatia J, Ojha S, Arya DS: Molecular Pathways Involved in the Amelioration of Myocardial Injury in Diabetic Rats by Kaempferol. Int J Mol Sci 2017, 18.

143. Feng H, Cao J, Zhang G, Wang Y: Kaempferol Attenuates Cardiac Hypertrophy via Regulation of ASK1/MAPK Signaling Pathway and Oxidative Stress. Planta Med 2017.

144.Zhou M, Ren H, Han J, Wang W, Zheng Q, Wang D: Protective Effects of Kaempferol against Myocardial Ischemia/Reperfusion Injury in Isolated Rat Heart via Antioxidant Activity and Inhibition of Glycogen Synthase Kinase-3beta. Oxid Med Cell Longev 2015, 2015:481405.

145. Suchal K, Malik S, Gamad N, Malhotra RK, Goyal SN, Chaudhary U, Bhatia J, Ojha S, Arya DS: Kaempferol Attenuates Myocardial Ischemic Injury via Inhibition of MAPK Signaling Pathway in Experimental Model of Myocardial Ischemia-Reperfusion Injury. Oxid Med Cell Longev 2016, 2016:7580731. 
146. Kim DS, Ha KC, Kwon DY, Kim MS, Kim HR, Chae SW, Chae HJ: Kaempferol protects ischemia/reperfusion-induced cardiac damage through the regulation of endoplasmic reticulum stress. Immunopharmacol Immunotoxicol 2008, 30:257-270.

147. Lin Y, Shi R, Wang X, Shen HM: Luteolin, a flavonoid with potential for cancer prevention and therapy. Curr Cancer Drug Targets 2008, 8:634-646.

148. Keli SO, Hertog MG, Feskens EJ, Kromhout D: Dietary flavonoids, antioxidant vitamins, and incidence of stroke: the Zutphen study. Arch Intern Med 1996, 156:637-642.

149. Hirvonen T, Virtamo J, Korhonen P, Albanes D, Pietinen P: Intake of flavonoids, carotenoids, vitamins $\mathrm{C}$ and E, and risk of stroke in male smokers. Stroke 2000, 31:23012306.

150. Nai C, Xuan H, Zhang Y, Shen M, Xu T, Pan D, Zhang C, Zhang Y, Li D: Luteolin Exerts Cardioprotective Effects through Improving Sarcoplasmic Reticulum $\mathrm{Ca}(2+)$-ATPase Activity in Rats during Ischemia/Reperfusion In Vivo. Evid Based Complement Alternat Med 2015, 2015:365854.

151. Hu W, Xu T, Wu P, Pan D, Chen J, Chen J, Zhang B, Zhu H, Li D: Luteolin improves cardiac dysfunction in heart failure rats by regulating sarcoplasmic reticulum Ca2+-ATPase 2a. Sci Rep 2017, 7:41017.

152. Kranias EG, Hajjar RJ: Modulation of cardiac contractility by the phospholamban/SERCA2a regulatome. Circ Res 2012, 110:1646-1660.

153. Kho C, Lee A, Jeong D, Oh JG, Chaanine AH, Kizana E, Park WJ, Hajjar RJ: SUMO1dependent modulation of SERCA2a in heart failure. Nature 2011, 477:601-605.

154. Blakeslee WW, Wysoczynski CL, Fritz KS, Nyborg JK, Churchill ME, McKinsey TA: Class I HDAC inhibition stimulates cardiac protein SUMOylation through a post-translational mechanism. Cell Signal 2014, 26:2912-2920.

155. Sinha K, Ghosh J, Sil PC: Morin and Its Role in Chronic Diseases. Adv Exp Med Biol 2016, 928:453-471.

156. Al-Numair KS, Chandramohan G, Alsaif MA: Pretreatment with morin, a flavonoid, ameliorates adenosine triphosphatases and glycoproteins in isoproterenol-induced myocardial infarction in rats. J Nat Med 2012, 66:95-101.

157.Prahalathan P, Saravanakumar M, Raja B: The flavonoid morin restores blood pressure and lipid metabolism in DOCA-salt hypertensive rats. Redox Rep 2012, 17:167-175.

158. Prahalathan P, Kumar S, Raja B: Effect of morin, a flavonoid against DOCA-salt hypertensive rats: a dose dependent study. Asian Pac J Trop Biomed 2012, 2:443-448.

159. Prahalathan P, Kumar S, Raja B: Morin attenuates blood pressure and oxidative stress in deoxycorticosterone acetate-salt hypertensive rats: a biochemical and histopathological evaluation. Metabolism 2012, 61:1087-1099.

160. Wu TW, Fung KP, Zeng LH, Wu J, Hempel A, Grey AA, Camerman N: Molecular properties and myocardial salvage effects of morin hydrate. Biochem Pharmacol 1995, 49:537-543.

161. Semwal DK, Semwal RB, Combrinck S, Viljoen A: Myricetin: A Dietary Molecule with Diverse Biological Activities. Nutrients 2016, 8:90.

162. Godse S, Mohan M, Kasture V, Kasture S: Effect of myricetin on blood pressure and metabolic alterations in fructose hypertensive rats. Pharm Biol 2010, 48:494-498.

163. Borde P, Mohan M, Kasture S: Effect of myricetin on deoxycorticosterone acetate (DOCA)salt-hypertensive rats. Nat Prod Res 2011, 25:1549-1559. 
164. Scarabelli TM, Mariotto S, Abdel-Azeim S, Shoji K, Darra E, Stephanou A, Chen-Scarabelli C, Marechal JD, Knight R, Ciampa A, et al: Targeting STAT1 by myricetin and delphinidin provides efficient protection of the heart from ischemia/reperfusion-induced injury. FEBS Lett 2009, 583:531-541.

165. Qiu Y, Cong N, Liang M, Wang Y, Wang J: Systems Pharmacology Dissection of the Protective Effect of Myricetin Against Acute Ischemia/Reperfusion-Induced Myocardial Injury in Isolated Rat Heart. Cardiovasc Toxicol 2016.

166. Tiwari R, Mohan M, Kasture S, Maxia A, Ballero M: Cardioprotective potential of myricetin in isoproterenol-induced myocardial infarction in Wistar rats. Phytother Res 2009, 23:13611366.

167.Zhang B, Shen Q, Chen Y, Pan R, Kuang S, Liu G, Sun G, Sun X: Myricitrin Alleviates Oxidative Stress-induced Inflammation and Apoptosis and Protects Mice against Diabetic Cardiomyopathy. Sci Rep 2017, 7:44239.

168. Zhang B, Chen Y, Shen Q, Liu G, Ye J, Sun G, Sun X: Myricitrin Attenuates High GlucoseInduced Apoptosis through Activating Akt-Nrf2 Signaling in H9c2 Cardiomyocytes. Molecules 2016, 21.

169. Sun J, Sun G, Cui X, Meng X, Qin M, Sun X: Myricitrin Protects against DoxorubicinInduced Cardiotoxicity by Counteracting Oxidative Stress and Inhibiting Mitochondrial Apoptosis via ERK/P53 Pathway. Evid Based Complement Alternat Med 2016, 2016:6093783.

170. Li LF, Lee CS, Lin CW, Chen NH, Chuang LP, Hung CY, Liu YY: Trichostatin A attenuates ventilation-augmented epithelial-mesenchymal transition in mice with bleomycin-induced acute lung injury by suppressing the Akt pathway. PLoS One 2017, 12:e0172571.

171. Chen J, Zhao H, Wang X, Lee FS, Yang H, Zheng L: Analysis of major alkaloids in Rhizoma coptidis by capillary electrophoresis-electrospray-time of flight mass spectrometry with different background electrolytes. Electrophoresis 2008, 29:2135-2147.

172. Yi J, Ye X, Wang D, He K, Yang Y, Liu X, Li X: Safety evaluation of main alkaloids from Rhizoma Coptidis. J Ethnopharmacol 2013, 145:303-310.

173. Kou S, Han B, Wang Y, Huang T, He K, Han Y, Zhou X, Ye X, Li X: Synergetic cholesterollowering effects of main alkaloids from Rhizoma Coptidis in HepG2 cells and hypercholesterolemia hamsters. Life Sci 2016, 151:50-60.

174. Tan HL, Chan KG, Pusparajah P, Duangjai A, Saokaew S, Mehmood Khan T, Lee LH, Goh BH: Rhizoma Coptidis: A Potential Cardiovascular Protective Agent. Front Pharmacol 2016, 7:362.

175. Kim YM, Ha YM, Jin YC, Shi LY, Lee YS, Kim HJ, Seo HG, Choi JS, Kim YS, Kang SS, et al: Palmatine from Coptidis rhizoma reduces ischemia-reperfusion-mediated acute myocardial injury in the rat. Food Chem Toxicol 2009, 47:2097-2102.

176. Lin X, Lin CH, Zhao T, Zuo D, Ye Z, Liu L, Lin MT: Quercetin protects against heat strokeinduced myocardial injury in male rats: Antioxidative and antiinflammatory mechanisms. Chem Biol Interact 2017, 265:47-54.

177. Bartekova M, Radosinska J, Pancza D, Barancik M, Ravingerova T: Cardioprotective effects of quercetin against ischemia-reperfusion injury are age-dependent. Physiol Res 2016, 65 Suppl 1:S101-107. 
178. Kumar M, Kasala ER, Bodduluru LN, Kumar V, Lahkar M: Molecular and biochemical evidence on the protective effects of quercetin in isoproterenol-induced acute myocardial injury in rats. J Biochem Mol Toxicol 2017, 31:1-8.

179. Jalili T, Carlstrom J, Kim S, Freeman D, Jin H, Wu TC, Litwin SE, David Symons J: Quercetin-supplemented diets lower blood pressure and attenuate cardiac hypertrophy in rats with aortic constriction. J Cardiovasc Pharmacol 2006, 47:531-541.

180. Annapurna A, Reddy CS, Akondi RB, Rao SR: Cardioprotective actions of two bioflavonoids, quercetin and rutin, in experimental myocardial infarction in both normal and streptozotocin-induced type I diabetic rats. J Pharm Pharmacol 2009, 61:1365-1374.

181. Punithavathi VR, Prince PS: Combined effects of quercetin and alpha-tocopherol on lipids and glycoprotein components in isoproterenol induced myocardial infarcted Wistar rats. Chem Biol Interact 2009, 181:322-327.

182. Egert S, Bosy-Westphal A, Seiberl J, Kurbitz C, Settler U, Plachta-Danielzik S, Wagner AE, Frank J, Schrezenmeir J, Rimbach G, et al: Quercetin reduces systolic blood pressure and plasma oxidised low-density lipoprotein concentrations in overweight subjects with a highcardiovascular disease risk phenotype: a double-blinded, placebo-controlled cross-over study. Br J Nutr 2009, 102:1065-1074.

183. Edwards RL, Lyon T, Litwin SE, Rabovsky A, Symons JD, Jalili T: Quercetin reduces blood pressure in hypertensive subjects. J Nutr 2007, 137:2405-2411.

184. Mira A, Shimizu K: In vitro Cytotoxic Activities and Molecular Mechanisms of Angelica shikokiana Extract and its Isolated Compounds. Pharmacogn Mag 2015, 11:S564-569.

185. Dohadwala MM, Vita JA: Grapes and cardiovascular disease. J Nutr 2009, 139:1788S1793 S.

186. Nambiar VS SN, Daniel M, Gallego EB: Flavonoids and phenolic acids from pearl millet (Pennisetum glaucum) based foods and their functional implications. Fun Food Health Dis 2012, 2:251-264.

187. Iyer A, Fenning A, Lim J, Le GT, Reid RC, Halili MA, Fairlie DP, Brown L: Antifibrotic activity of an inhibitor of histone deacetylases in DOCA-salt hypertensive rats. $\mathrm{Br} \mathrm{J}$ Pharmacol 2010, 159:1408-1417. 